\title{
BIOTECHNOLOGY, COMMUNICATION AND THE PUBLIC

\author{
KEYS TO DELVE INTO THE SOCIAL PERCEPTION OF SCIENCE
}

DOMINIQUE BROSSARD

The latest biotechnology applications allow for faster and cheaper gene editing than ever before. Many people are calling for a public debate on these issues, including the social, cultural and ethical implications of these applications. On the other hand, the information available to citizens is sometimes contradictory and communication that takes all these aspects into account is important and increasingly necessary. Therefore, understanding public attitudes towards biotechnology should be a priority for the work ahead.

Keywords: biotechnology, communication, public understanding of science, genetic engineering, GMOs.

Market applications of biotechnology have become commonplace, and new ones are appearing at a fast pace. Recently, the new gene editing tool CRISPR/ Cas9 has made gene editing faster, easier and cheaper, and agricultural products using the technique (i.e., the non-browning Arctic ${ }^{\circledR}$ apples) are already in the hands of the consumers in the United States. Applications in the human context are also becoming reality, with the journal Nature announcing in August 2017 that for the first time, a gene responsible for heart failure had been successfully edited in a human embryo using CRISPR/ Cas9 (Ma et al., 2017). At the same time, regulations related to these scientific breakthroughs are still in flux. With many calling for broad public debates on these questions and citizens being confronted with often conflicting information, communication about these techniques is more than ever important.

So, what is biotechnology? Broadly construed, it is «the manipulation (as through genetic engineering, or GE) of living organisms or their components to produce useful commercial products» (MerriamWebster, 2018). The use of biotechnology in food contexts has been a reality for a long time (with some claiming that brewing techniques in beer-making are a form of biotechnologies), and the first commercial GE crop (a GE tomato with delayed ripening) was approved for commercial sale in the United States in the mid-1990s. GE crops are now grown on more than $12 \%$ of the world cropland, with close to $40 \%$ of this acreage being in the United States (National Academies of Sciences, Engineering, and Medicine, 2016). As is often the case with technologies that have not only scientific, but also legal, social and ethical dimensions, GE crops (and related genetically engineered foods, frequently called «GMOs») have been surrounded with controversy. Indeed, many around the world have voiced concerns about the potential risks posed by genetic engineering, while many others have stressed their potential benefits (see Brossard, 2012, for a review).

\section{UNDERSTANDING PUBLIC ATTITUDES TOWARD BIOTECHNOLOGIES}

It is well established that most citizens around the world do not know much about biotechnologies and their potential applications in agriculture and human health, but this has not prevented controversies around their use to flourish (Brossard, Nesbitt, \& Shanahan, 2007; Brossard, 2012). And although there is scientific 
consensus that consuming GE crops does not pose a risk to human health - based on experiences to date, which are mostly restricted to herbicide resistant and insect resistant varieties of corn, cotton, and soybean (National Academies of Sciences, Engineering, and Medicine, 2016) -, a large number of consumers worldwide are still worried these technologies are dangerous to human health, among other concerns. So, is this a communication problem?

It might be a communication problem, but it is certainly not a knowledge deficit problem. It is well established that ignorance (or misunderstanding) of established scientific facts is often not the main reason why people reject scientific innovations (see Akin \& Scheufele, 2017, for a review). Instead, individuals rely on cues provided by their values, their perceptions of the risks and benefits involved, their level of trust in the different information providers, and by how they see these issues covered in the media, to name just a few of the mental shortcuts people use to form attitudes toward controversial science (Brossard \& Nisbet, 2007; National Academies of Sciences, Engineering, and Medicine, 2016, 2017). People process information related to biotechnologies based on their preexisting values and beliefs, a process known as «motivated reasoning» (Kunda, 1990; Yeo, Cacciatore, \& Scheufele, 2015). In practical terms, this means that the same message about a scientific development such as biotechnology and its applications can be interpreted very differently by two individuals. According to this line of research, we all process information (including scientific evidence) in biased ways, and we use our religious views (Ho, Brossard, \& Scheufele, 2008; Brossard, Scheufele, Kim, \& Lewenstein, 2009), our cultural values (Kahan, Braman, Slovic, Gastil, \& Cohen, 2009), or our deference to science (Brossard \& Nisbet, 2007) among other values, to make sense of information about new, controversial technologies such as genetic engineering. More importantly, by processes called «confirmation bias» (and «disconfirmation bias»), we tend to give more importance to the information that confirms our beliefs and discard the one that does not (Yeo, Xenos, Brossard, \& Scheufele, 2015).

This has important consequences for communication about biotechnology. When individuals express concerns about the potential health effects of consuming GMOs, even when knowing most scientists agree there is no evidence of such effects, they might not do so because they distrust science, or because they are ignoring science facts, as it is often argued. Rather, such individuals

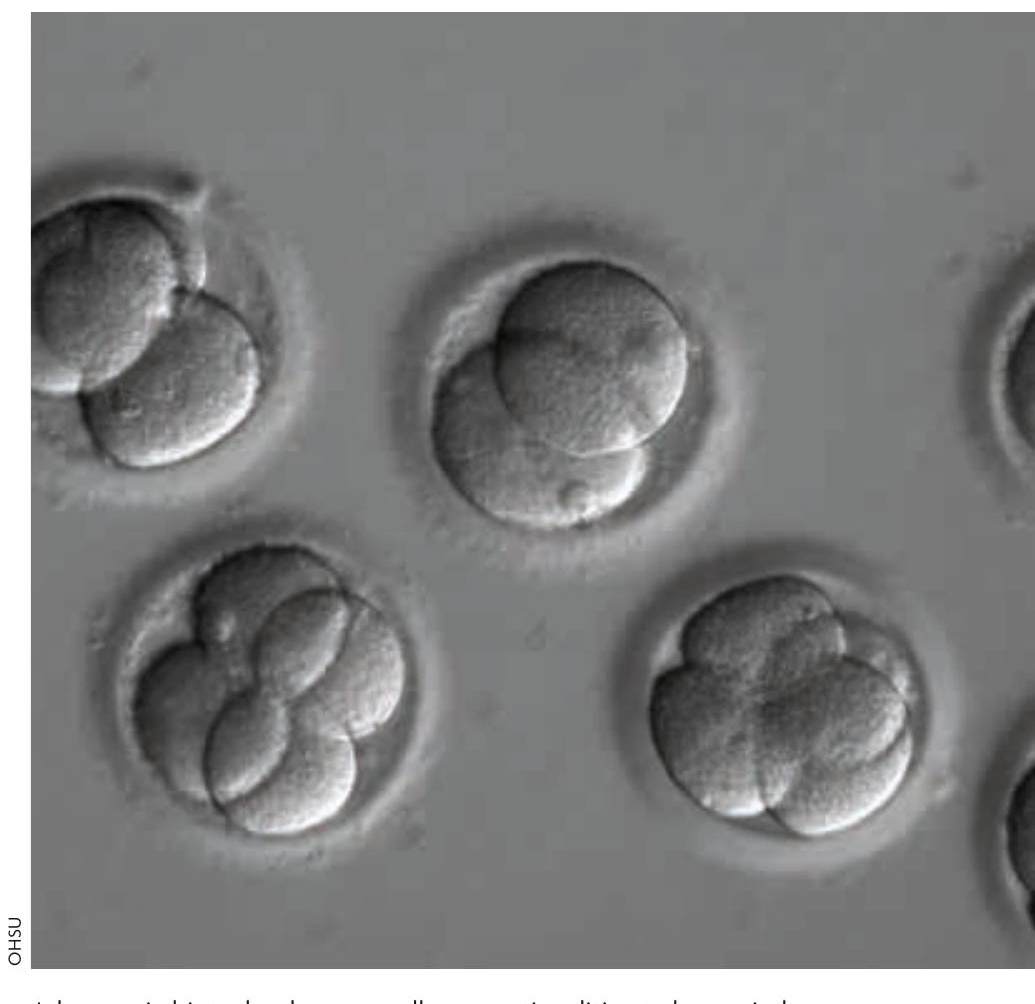

Advances in biotechnology now allow genetic editing to be carried out more quickly and economically, even in the human context. In 2017, Nature published the results of a study that successfully modified a gene related to heart failure in human embryos using the CRISPR/Cas9 technique. In the picture, embryos after the coinjection of a gene- and sperm-correcting enzyme from a donor with a genetic mutation causing hypertrophic cardiomyopathy.

"AS IS OFTEN THE CASE WITH TECHNOLOGIES THAT HAVE MORE THAN SCIENTIFIC DIMENSIONS, GE CROPS HAVE BEEN SURROUNDED WITH CONTROVERSY» 


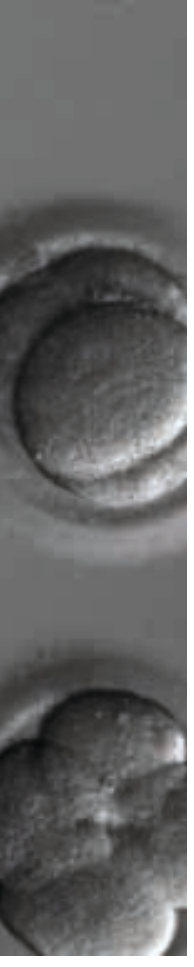

may be giving more weight to fringe scientific studies that have concluded these health effects do exist (such as the widely circulated, although retracted, «Séralini study») than to the vast number of studies that have concluded otherwise (for a discussion of the Séralini study, see National Academies of Sciences, Engineering, and Medicine, 2016). In this hypothetical case, individuals might be concerned by the potential health effects of GMOs because they do not trust the regulatory system that is supposed to keep their food safe or because they distrust the corporations that are producing GMOs and industrial agriculture in general, to cite a few potential scenarios. Alternatively, they may feel that GMOs are unnatural and are messing up with nature and therefore should be avoided. These individuals will find the science that supports their beliefs to make their case, even if this science does not meet the quality standards expected by the scientific community and is expressed in a retracted peerreviewed article.

Insights from risk communication research are also important to take into account: public

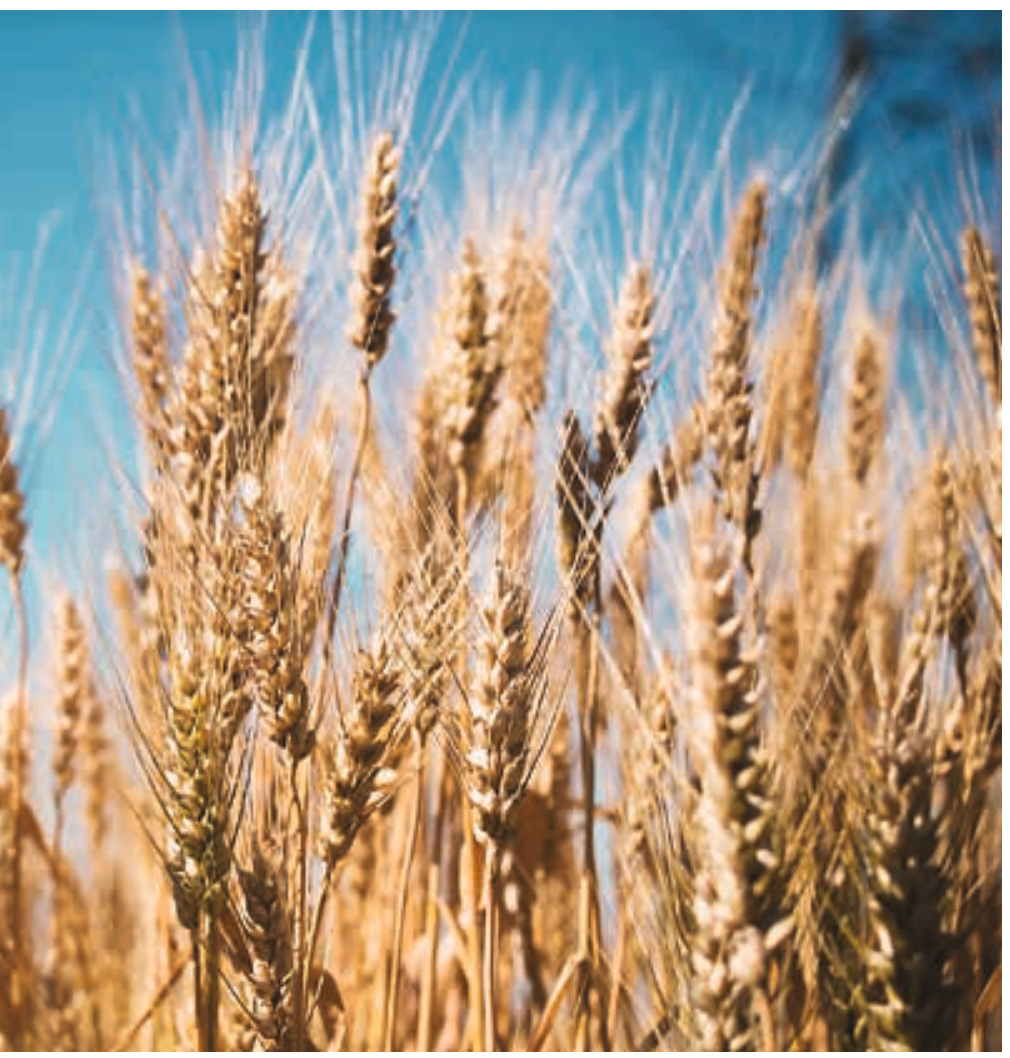

The use of biotechnology in the food sector has long been a reality. Genetically engineered crops account for more than $12 \%$ of the world's cultivated land

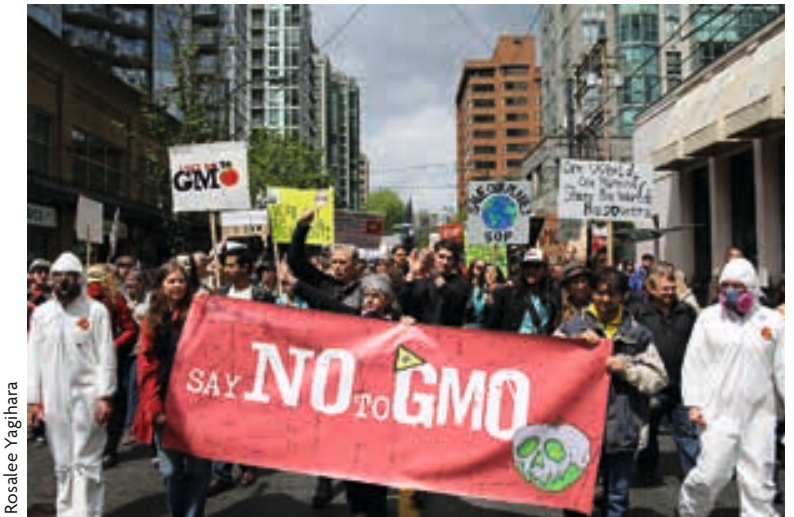

The scientific community agrees that consuming genetically modified crops is safe. However, consumers around the world remain concerned that these foods are dangerous to human health. In the picture, a demonstration against GMOs in Vancouver (Canada) in 2013.

\section{"WE TEND TO GIVE MORE IMPORTANCE TO THE INFORMATION THAT CONFIRMS OUR BELIEFS AND DISCARD THE ONE THAT DOES NOT»}

perceptions of the risks related to biotechnologies have more to do with the outrage (or negative emotional response) the technology provokes, rather than the hazard the technology poses in probabilistic terms. The more dreaded the technology, the more outrage it produces, and this dread may be linked to factors hard to measure with a purely technical risk assessment approach. Indeed, individuals may be expressing concerns about health or environmental risks, while be more generally concerned about the social, cultural and ethical implications of the technology (National Academies of Sciences, Engineering, and Medicine, 2016; see Covello, 2010 for an overview of risk communication principles). With online environments providing platforms for individuals to share their outrage about new technologies and potentially contributing to the social amplification of the risks perceived, an understanding of the communication processes at play in these environments is crucial.

\section{COMMUNICATION ABOUT BIOTECHNOLOGIES AND ONLINE MEDIA ENVIRONMENTS}

Although there are clear disparities between advanced economies and the developing world in 


\section{biotechnol}

\section{biotechnology} biotechnology and bioengineering biotechnology projects biotechnologist biotechnology advances biotechnology progress biotechnology degree biotechnology for biofuels biotechnology news L:atashnology journal

terms of Internet access (more individuals in North America and Europe have access to the Internet, compared with other parts of the world), access and use are growing rapidly around the globe (Pew Research Center, 2016). In practical terms, this means that people can have access to virtually unlimited information about anything, anywhere. However, when people search for information online about issues such as biotechnologies, the results presented by the search algorithms will take into account their previous searches as well as their other online behaviors. Search results will therefore make it likely individuals will be exposed mostly to information that supports their views, phenomena that have been labeled «filter bubbles». Individuals are also likely to connect online with others who think like them, reinforcing in the process their own point of view through «echo-chambers», sharing
Currently, we have access to a virtually unlimited amount of information on anything, but when a user searches the Internet for information on a topic, the search algorithms take their previous searches and web behaviour into account, so the results obtained reinforce their own information. This is known as a «filter bubble».

«INTERNET SEARCH RESULTS WILL THEREFORE MAKE IT LIKELY INDIVIDUALS

WILL BE EXPOSED MOSTLY TO INFORMATION THAT SUPPORTS THEIR VIEWS" 
information about topics of interest on a multitude of social networks and writing their own content

(Brossard, 2013, 2014).

Information about biotechnologies encountered online is not found in isolation. Unlike traditional, print news content, online news is contextualized by other readers, who can like or dislike content, post comments, and re-share content, with this contextualization having important effects on public attitudes toward technologies and on perceptions of the news media. Notably, rude comments following a science news story about nanotechnologies were shown to have a «nasty effect» on the readers, with those exposed to the rude comments ending up being more polarized about the technologies that those exposed to civil comments (Anderson, Brossard, Scheufele, Xenos, \& Ladwig, 2013). And although the growth in the use of social media for news content is leveling somewhat - people are more and more using messaging applications such as Whatsapp to access news content (Reuters Institute, 2017) -, the importance of online cues provided by readers on stories about biotechnologies cannot be dismissed. Likewise, the complexities of a science in constant evolution should also be taken into account, as perfectly illustrated by CRISPR/Cas9 and its use in human gene editing.

\section{COMMUNICATION IN AN ERA OF POST NORMAL} SCIENCE

CRISPR/Cas9, the technology making gene editing easier, more precise and cheaper mentioned at the start of this essay, is a perfect illustration of what has been called post normal science. When 'facts are uncertain, values in dispute, stakes high and decisions urgent' (Funtowicz \& Ravetz, 1992), policy debates have to go beyond the scientific community for expert input and need to include many voices. The CRISPR/Cas9 technology could potentially help eradicate human genetic diseases such as sickle cell anemia, but could also be used to enhance the human body and create designer babies. If germline editing is performed, the changes could be transmitted to future generations. While the myriad of ethical, legal and social implications of such applications have been extensive discussed (see National Academies of Sciences, Engineering, and Medicine, 2017), scientific research continues to advance at fast pace, some may say at a pace faster than the capacity for societies to develop adequate regulatory frameworks for such research and its applications.

And lay individuals want to be active participants in policy discussions about gene editing in general and human gene editing in particular. A recent survey of American adults found that public concerns do not match experts' views of human gene editing (Scheufele et al., 2017). While the latter are concerned about the heritability of germline editing (that would be performed for therapeutic or enhancement reasons), the majority of Americans find the use of human genome editing for therapeutic purposes acceptable when achieved through either somatic or germline edits. However, when gene editing is used for human enhancement purposes, public opposition increases. More importantly, most respondents are in agreement that the scientific community «should consult with the public before applying gene editing to humans» (Scheufele et al., 2017) which brings us back to the concept of post normal science mentioned above and to communication related issues.

In an editorial published on 22 February 2017, the journal Nature perfectly illustrated the current complexities of the legal landscape for gene editing technologies used in plants. The editors stressed the politicized nature of the debate in Europe as far as potential regulations were concerned as well as the unclear legal status of plant products produced with the CRISPR/Cas9 technology. Additionally, the editors called for plant scientists to engage with the public to discuss the issue and claimed that «reason and science need[ed] to prevail this time» and the safety and value of gene editing should therefore be widely communicated (Nature, 2017). Unfortunately, most scientists are not trained at communication and real, meaningful engagement is difficult and costly. Public engagement exercises that do not take into account public concerns and are not bi-directional are unlikely to be productive and may even backlash. At the end of the day, very often questions raised in public settings cannot be answered by science alone because they go beyond the technical aspects of the issue, as we discussed earlier on.

The release of a recent consensus report on genetically engineered crops by the National Academies of Sciences in the United States provides an example of sound communication about biotechnology. The report summarized the consensus 
of a committee of international experts from a wide range of disciplines regarding the potential agronomical, environmental, health and socio-economic impacts of genetically engineered crops. It also discussed the regulatory issues GE crops raised (National Academies of Sciences, Engineering, and Medicine, 2016). The committee made every effort to address public concerns by answering all questions raised during the public meetings and through the website of the study ${ }^{1}$. The report acknowledged that GE was more than a technical issue, and that some of the questions raised did not have a simple right/wrong simple answer. Indeed, many of the report conclusions came with caveats. Additionally, the committee researched all funding sources for the scientific studies reviewed and made the information available through the online report. More importantly, the release of the report was followed by extensive communication with media outlets and public presentations, further discussions with various stakeholders and follow up publications (see Gould et al., 2017). In sum, the report did generate fruitful and constructive discussions about the topic, which should be the goal of any good communication exercise.

\section{MOVING FORWARD}

Communication about biotechnologies is complex since it needs to take into account the social, cultural, and political contexts in which the technologies are deployed and the many issues they raise. Debates related to biotechnologies have often more to do with the ethical, legal and social implications of the use of the technologies rather than with the science itself. Communication about biotechnologies has therefore to go beyond the communication of established scientific facts and has to start with an understanding of the public audiences and of their concerns. It is therefore crucial that all scientists involved acknowledge that the questions raised often do not have simple answers and that it is legitimate for the public to raise questions that go beyond the science. It is also important to recognize that individuals form attitudes toward new technologies through complex mechanisms and that simply explaining scientific facts or communicating consensus might fall short.
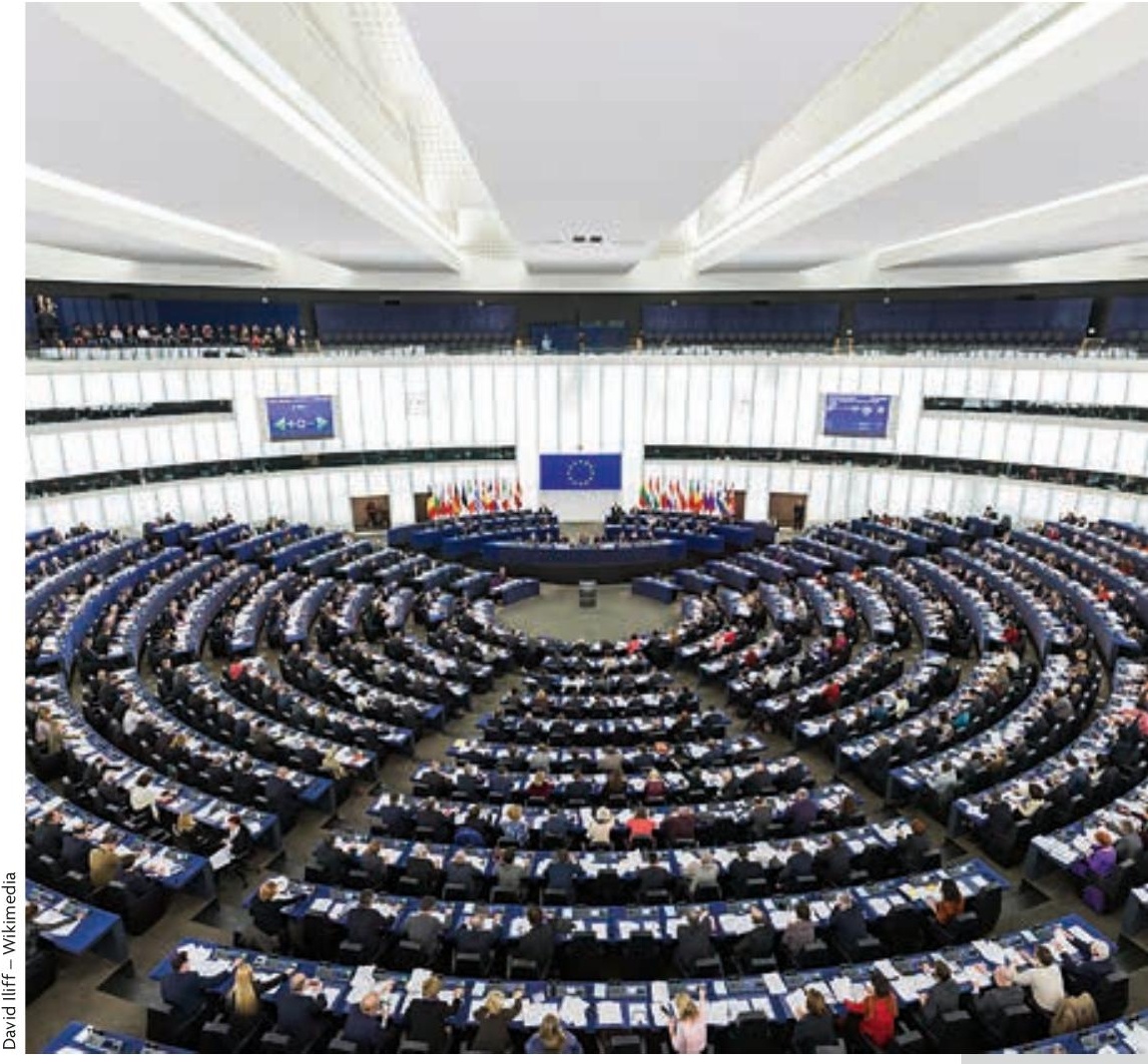

In 2017 Nature pointed out the political nature of the European debate on the regulation of plants produced with CRISPR/Cas9 technology. The editors urged the scientific community to get involved in the public discussion. In the picture, a session of the European Parliament.

\author{
"PUBLIC PERCEPTION OF THE RISKS \\ RELATED TO BIOTECHNOLOGY HAVE \\ MORE TO DO WITH THE OUTRAGE \\ THE TECHNOLOGY PROVOKES, RATHER \\ THAN THE HAZARD THE TECHNOLOGY \\ POSES"
}


